\title{
Gene Promoter Methylation and Its Potential Relevance in Early Prostate Cancer Diagnosis
}

\author{
Isabel Steiner ${ }^{a, c}$ Klaus Jung ${ }^{b, c}$ Philipp Schatz ${ }^{d}$ Torsten Horns ${ }^{d}$ \\ Daniel Wittschieber $^{a}$ Michael Lein $^{b}$ Manfred Dietel $^{a}$ Andreas Erbersdobler $^{\mathrm{e}}$ \\ anstitute of Pathology and ${ }^{b}$ Department of Urology, Charité-Universitätsmedizin Berlin, ${ }^{\mathrm{c} B e r l i n}$ Institute for \\ Urologic Research, and dEpigenomics AG, Berlin, and eInstitute of Pathology, University of Rostock, \\ Rostock, Germany
}

\section{Key Words}

Promoter hypermethylation - GSTP1 - RAR $\beta 2$ - Prostate cancer $\cdot$ Field effect

\begin{abstract}
Aims: We investigated hypermethylation of the glutathione S-transferase pi (GSTP1), retinoic acid receptor $\beta 2$ (RARß2), adenomatous polyposis coli (APC) and paired-like homeodomain transcription factor 2 (PITX2) gene promoters which could serve as a sensitive tool to indicate a risk of prostate cancer even in histologically tumor-free tissues. Methods: Tumor tissues and non-neoplastic tissues at variable distances from the tumor foci were retrieved from 25 formalin-fixed and paraffin-embedded prostatectomy specimens and subjected to DNA extraction. The methylation levels were assessed by means of different assay technologies. $\boldsymbol{R e}$ sults: Significantly increased methylation levels in cancer specimens were found for all promoter regions (GSTP1: 21/25, 84\%; RARß2: 24/25, 96\%; APC: 21/25, 84\%; PITX2: $20 / 25,80 \%$ ) and in most samples containing prostatic intraepithelial neoplasia. Several samples showed increased RAR $\beta 2$ and APC methylation in adjacent non-neoplastic tissue. An association between the methylation extent of GSTP1, APC and RARß2, respectively, and primary Gleason
\end{abstract}

grade was detectable. GSTP1 methylation was also associated with extraprostatic tumor extension. Conclusion: GSTP1, APC, RAR $\beta 2$ and PITX2 methylation occur frequently in prostate cancer, making these markers sensitive tools for the detection of neoplastic lesions in the prostate. For RAR $\beta 2$, the results suggest a kind of methylation field effect which could be helpful for the detection of prostate cancer. Larger studies are necessary to investigate a potential correlation of GSTP1, RAR $\beta 2$ and APC hypermethylation with tumor aggressiveness.

Copyright $\odot 2010$ S. Karger AG, Basel

\section{Introduction}

Although the prostate-specific antigen (PSA) serum level is the most important tool for prostate cancer (PCa) detection, it suffers from poor sensitivity and specificity $[1,2]$. Additionally, core needle biopsies often need to be carried out repeatedly just because the first biopsy failed to detect the tumor [3]. Therefore, new molecular biomarkers which indicate the presence or absence of tumor cells in an early tumor stage are clearly necessary.

Gene promoter hypermethylation resulting in expression silencing has recently been identified as an epigen-

\section{KARGER}

Fax +41613061234

E-Mail karger@karger.ch

www.karger.com
(C) 2010 S. Karger AG, Basel

$1015-2008 / 10 / 0775-0260 \$ 26.00 / 0$

Accessible online at:

www.karger.com/pat
Isabel Steiner

Institute of Pathology and Berlin Institute for Urologic Research

Charité University Hospital Berlin

Charitéplatz 1, DE-10117 Berlin (Germany)

Tel. +4930450515 043, Fax +4930450515 904, E-Mail isabel.steiner@charite.de 
etic alteration in cancer [4-6]. Elevated promoter methylation in prostatic intraepithelial neoplasia (PIN) and carcinoma was primarily shown for the glutathione Stransferase pi (GSTP1) and the retinoic acid receptor $\beta 2$ (RAR $\beta 2$ ) [7-10]. The adenomatous polyposis coli (APC) gene was also demonstrated to be inactivated by genetic and epigenetic mechanisms in various malignancies including $\mathrm{PCa}[11,12]$. In addition, its promoter hypermethylation was recently reported as a marker for poor prognosis in prostate biopsy specimens [13]. Hypermethylation of the paired-like homeodomain transcription factor 2 (PITX2) gene has been shown to be an independent prognostic factor for biochemical recurrence (PSA relapse) after radical prostatectomy in PCa patients [14].

In 1953, the term 'field cancerization' was introduced for the first time [15]. It claims that cancer arises simultaneously in multiple tissue areas under the influence of certain carcinogenic agents. Thus, it seems possible that pathological and genetic changes can already be detected next to a given tumor [16]. As gene promoter hypermethylation has been demonstrated to be an early event in carcinogenesis, analyzing this epigenetic modification in histologically normal tissue could be a promising method for identifying patients at risk for PCa.

Although some of the above mentioned genes were already investigated in $\mathrm{PCa}$, the results are sometimes contradictory $[17,18]$. Therefore, we analyzed tumor and tumor-adjacent tissues of a set of well-characterized prostatectomy specimens for a putative methylation field effect, which may be an indicator for PCa even in histologically tumor-free tissue.

\section{Materials and Methods}

\section{Sample Collection}

Twenty-five formalin-fixed and paraffin-embedded prostatectomy specimens and 6 control tissues (5 PCa-free cystoprostatectomy specimens and 1 benign prostatic hyperplasia), all obtained in 2008, were collected in accordance to the institutional ethical guidelines. Clinicopathologic parameters of all patients are listed in table 1 .

\section{DNA Isolation and Sodium Bisulfite Treatment}

Initially, prostatectomy specimens were carefully mapped for tumor foci by an experienced pathologist (A.E.). Guided by histological step sections, cores from control tissues as well as tumor tissue and tumor-adjacent tissue from the same paraffin block at exactly determined distances from PCa were retrieved for genomic DNA isolation using a punching device with a diameter of 1.5 $\mathrm{mm}$ (see table 1 for distances). Genomic DNA was extracted using the QIAamp ${ }^{\circledR}$ DNA FFPE Tissue Kit (Qiagen, Hilden, Germany). Conversion of $2 \mu \mathrm{g}$ genomic DNA by bisulfite treatment was per-

DNA Promoter Methylation in Prostate

Cancer formed using the EpiTect ${ }^{\circledR}$ Bisulfite Kit (Qiagen) according to the manufacturer's protocol. DNA samples were stored at $-20^{\circ} \mathrm{C}$ up to polymerase chain reaction (PCR)-based quantification.

\section{Quantitative PCR-Based Assays}

GSTP1 methylation quantification was performed with the HeavyMethyl ${ }^{\circledR}$ technology as described by Distler [19]. The LightMix ${ }^{\circledR}$ GSTP1 Kit (for methylated GSTP1) and the LightMix Reference G Kit (for the whole GSTP1 amount) were used according to the manufacturer's protocol (Epigenomics AG, Berlin, Germany). Standard curves for quantification were generated using Bisulfite DNA Quantification Standards (Epigenomics) and EpiTect PCR Control DNA (Qiagen) as templates. PITX2 gene methylation was measured using the EpiTect MethyLight ${ }^{\circledR}$ PCR Kit (Qiagen) and the EpiTect MethyLight Assay: Hs_PITX2 primer mix (Qiagen) as described in the manufacturer's manual. RAR $\beta 2$ and APC gene methylation were measured using TaqMan ${ }^{\circledR}$ technology with well-established primers $[10,20]$. Primer and probe sequences were as follows: 5'-CGAGAACGCGAGCGATTC-3' (RARß2 sense), 5'-CAAACTTACTCGACCAATCCAACC-3' (RAR 32 antisense), 6FAM5'-TCGGAACGTATTCGGAAGGTTTTTTGTAAGTATTT-3'BBQ (RAR $\beta 2$ probe) and 5'-GAACCAAAACGCTCCCCAT-3' (APC sense), 5'-TTATATGTCGGTTACGTGCGTTTATAT-3' (APC antisense), 6FAM5'-CCCGTCGAAAACCCGCCGATTA-3'BBQ (APC probe), respectively. $\beta$ Actin (ACTB) served as internal reference gene for total DNA quantification: 5'-TGGTGATGGAGGAGGTTTAGTAAGT-3' (ACTB sense), 5'-AACCAATAAAACCTACTCCTCCCTTAA-3' (ACTB antisense), 6FAM-5'-ACCACCACCCAACACACAATAACAAACACA-3'-PH (ACTB probe).

For all PCR-based assays, 25 ng bisulfite-converted DNA per reaction was used. DNA quantification was performed on a Roche LightCycler 480 Instrument in 96-well plates. All samples were measured in duplicates in a reaction volume of either $20 \mu \mathrm{l}$ (GSTP1, PITX2) or $10 \mu \mathrm{l}$ (RARß2, APC, ACTB). Each PCR run included positive controls (bisulfite-converted universally methylated human DNA) and water blanks. To calculate the percent methylation, the amount of methylated GSTP1 was divided by the whole amount of GSTP1 multiplied by 100 . As PITX2 methylation was determined in a dual-color quantitative PCR, a color compensation file for FAM and VIC fluorescence was generated as described in the LightCycler 480 manual. Using the threshold cycles determined by the individual TaqMan probe dye, methylation ratios were calculated with the fit point method as follows: PITX2 (\%) $=100 /(1+$ $\left.2^{(\mathrm{Ct}(\mathrm{FAM})-\mathrm{Ct}(\mathrm{VIC}))}\right)$ [21]. RAR $\beta 2$ and APC methylation ratios were calculated as the concentration for methylated RAR $\beta 2$ (APC) divided by the amount of unmethylated ACTB multiplied by 100 .

\section{Identification of the Relative Limit of Detection}

To verify the relative limit of detection, we used different amounts, from $25 \mathrm{ng}$ to $0.25 \mathrm{pg}$ (100-0.0001\%), of fully methylated, bisulfite-converted DNA (Qiagen) diluted in unmethylated bisulfite-converted human DNA (Qiagen). The lowest ratio with a still well-detectable fluorescence signal was used as the cut-off value for further analysis.

\section{Statistical Analysis}

Statistics were carried out with GraphPad Prism 5.0 Software (Graph Pad Software, San Diego, Calif., USA). The Kruskal-Wallis test was performed to compare methylation ratios of $\mathrm{PCa}$, ad- 
Table 1. Clinical and pathological characteristics of patients and tissues retrieved from prostatectomy specimens

a Patients

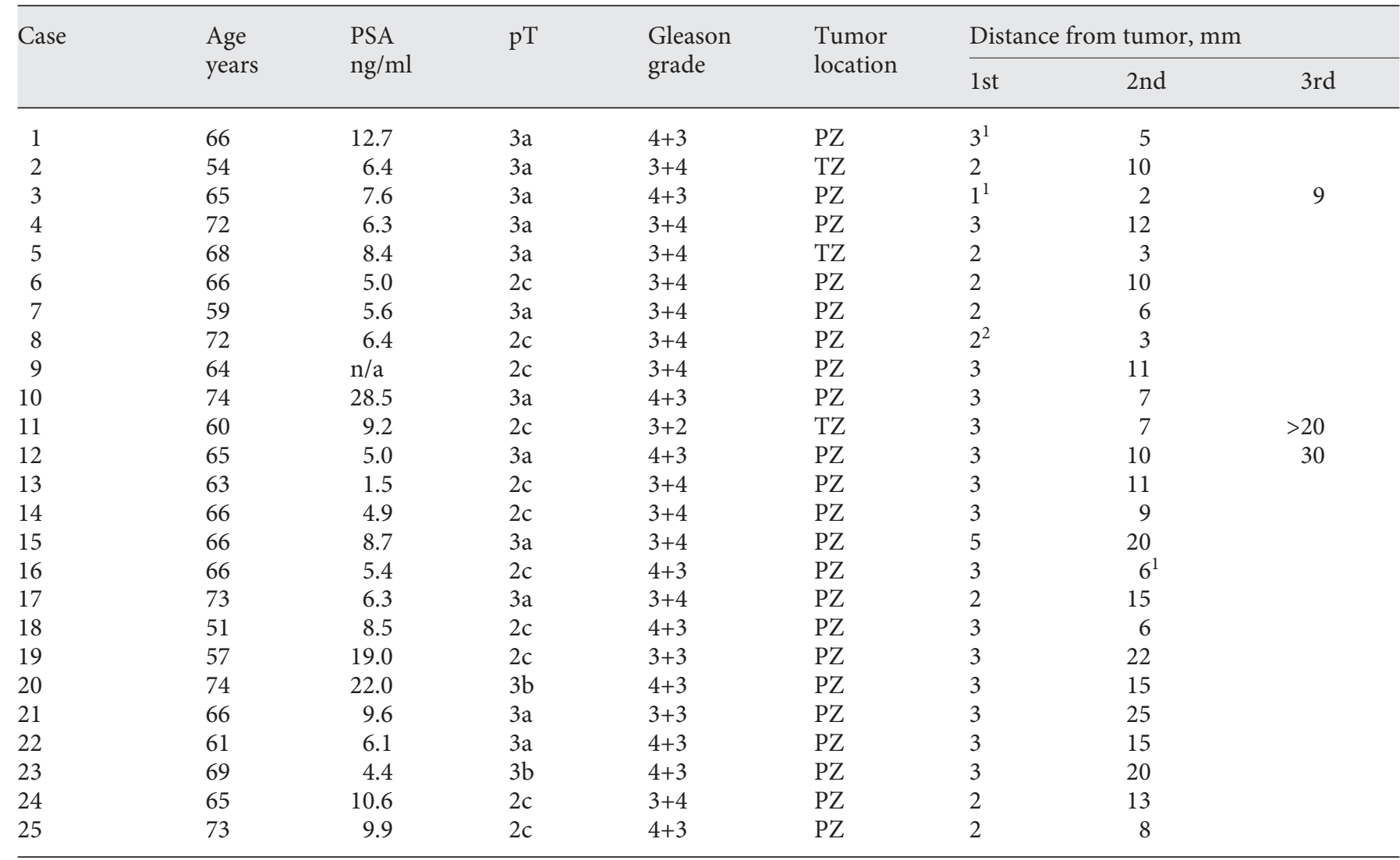

b Controls

\begin{tabular}{lll}
\hline Case & $\begin{array}{l}\text { Age } \\
\text { years }\end{array}$ & Origin \\
\hline Con1 + Con2 & 73 & PCa-free cystoprostatectomy; samples taken from 2 different regions \\
Con3 & 57 & BPH \\
Con4 & 68 & PCa-free cystoprostatectomy \\
Con5 & 78 & PCa-free cystoprostatectomy \\
Con6 & 18 & PCa-free cystoprostatectomy \\
\hline
\end{tabular}

$\mathrm{PZ}=$ Peripheral zone; $\mathrm{TZ}=$ transition zone; $\mathrm{Con}=$ control tissue; $\mathrm{BPH}=$ benign prostatic hyperplasia.

${ }^{1}$ PIN. ${ }^{2}$ Atrophy.

jacent and control tissues. To analyze the relationship between the methylation levels and $\mathrm{pT}$ stage or primary Gleason grade, we compared the median of each group of tissue samples by using the Mann-Whitney U test. Methylation ratios and age were correlated using the Spearman rank test. All statistical tests were 2-sided, and a value $<0.05$ was considered statistically significant.

\section{Results}

For gene hypermethylation analysis, we tested a total number of 78 tissue samples retrieved from 25 patients who underwent radical prostatectomies. The samples of each patient included 1 tumor sample and at least 2 different tumor-adjacent specimens at variable distances to 


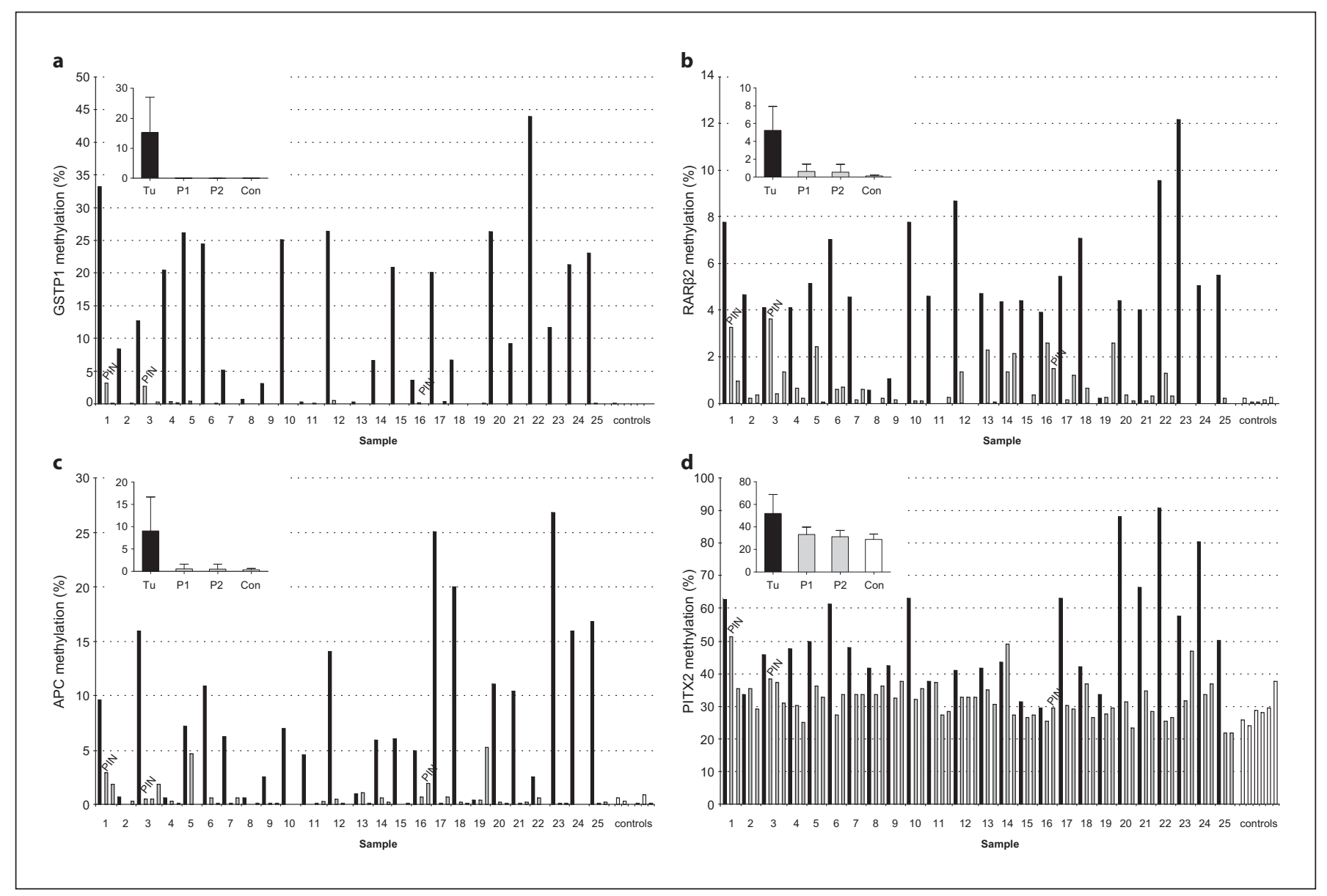

Fig. 1. Gene promoter hypermethylation of GSTP1 (a), RAR 2 (b), APC (c) and PITX2 (d) in prostate cancers (black bars), adjacent tissues (grey bars) and controls (white bars) demonstrated for each sample. Inserted plots illustrate individual mean values of the methylation ratios in tumor samples ( $\mathrm{Tu}$ ), peritumoral tissues [retrieved close (P1) or distant (P2) to the tumor area] and PCa-free controls (Con), respectively. Error bars represent standard deviations.

the tumor areas. Genomic DNA could be isolated in all biopsies and after bisulfite conversion; methylation ratios were successfully quantified by methylation-specific PCR assays.

After analyzing the relative limit of detection, we were able to detect $1 \%$ ( $0.1 \%$ for RAR $\beta 2$ and APC, respectively) methylated GSTP1 in a background of fully unmethylated DNA. Thus, methylation ratios $<1 \%$ ( $0.1 \%$ for RAR $\beta 2$ and APC, respectively) were considered to be methylation negative.

Control tissues consisting of PCa-free cystoprostatectomies and benign prostatic hyperplasia showed no (GSTP1), low (RAR $\beta 2$, APC) or moderate (PITX2) methylation, with the highest ratios being $0.27 \%$ (RAR $\beta 2$ ), $0.89 \%$ (APC) and $37.61 \%$ (PITX2). These ratios given by the control samples were used as cut-off values to analyze the calculated ratios of the different samples.

\section{Gene Promoter Methylation Is a Frequent Event in $P C a$ and PIN}

Compared with tumor-adjacent and control tissues, $84 \%(21 / 25)$ of all tumor samples and 2 of 3 PIN foci showed significantly increased GSTP1 hypermethylation ranging from 2.7 to $44.0 \%$ ( $\mathrm{p}=0.0001$; fig. 1a), whereas the GSTP1 methylation in benign adjacent tissue did not differ from the control ratios.

Almost all tumor tissues $(24 / 25,96 \%)$ showed substantial RAR 32 methylation (0.57-12.2\%; fig. $1 \mathrm{~b})$, and all 3 PIN foci were also strongly methylated (3.26, 3.59 and $1.49 \%$, respectively). More than half of the tumor-adja- 


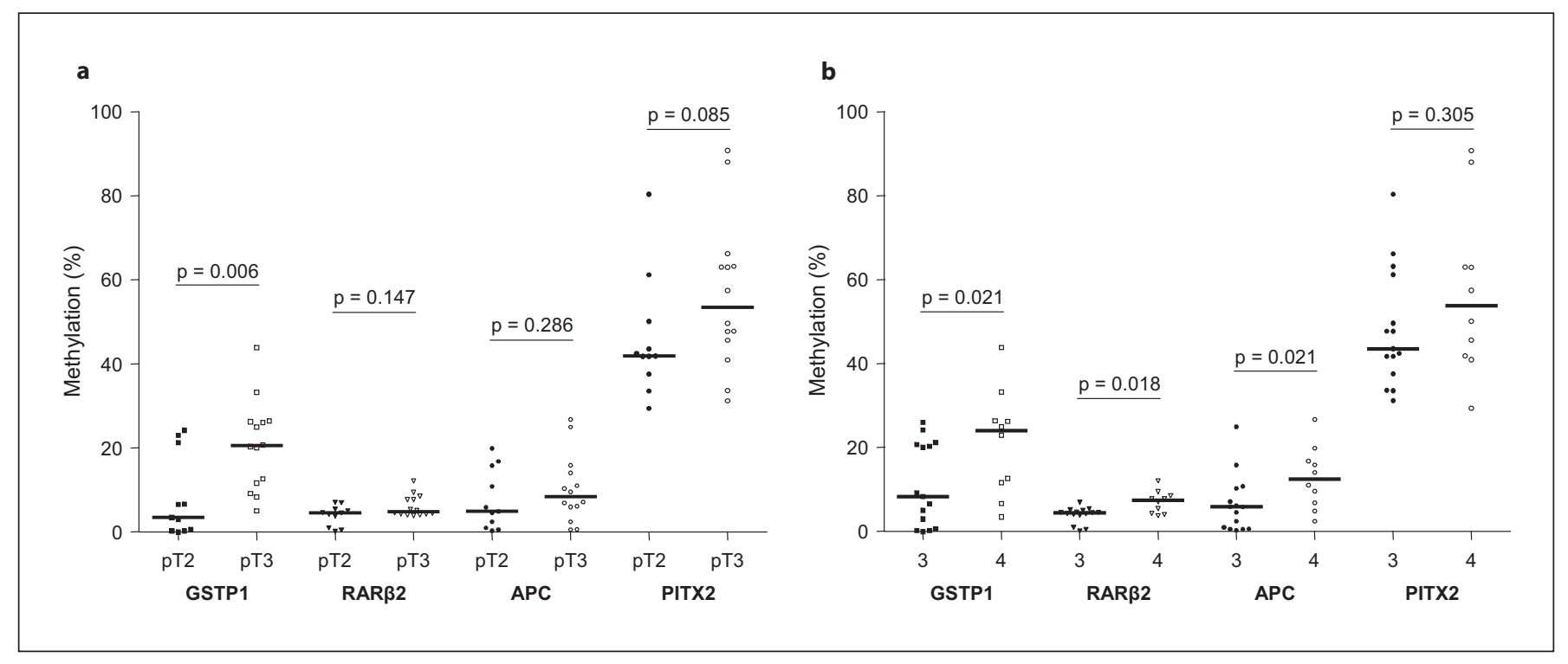

Fig. 2. Association of tumor methylation with pT category (a) and primary Gleason grade (b).

cent tissue samples $(18 / 25,72 \%)$ demonstrated elevated RAR 32 methylation either in 1 or both biopsies. Only sample 19 showed no tumor methylation, but an increased ratio (2.55\%) $22 \mathrm{~mm}$ away from the tumor site. Histological re-examination of that region excluded the existence of PIN or PCa.

Significantly increased methylation within the APC promoter (1.0-26.8\%) was determined in 21 (84\%) tumor specimens and 2 PIN foci ( $<<0.0001$; fig. 1c). Five cases $(1,3,5,13$ and 19) showed increased APC methylation adjacent to the tumor. Again, sample 19 demonstrated no methylation in the tumor, but an increased level in tumor-adjacent tissue more than $20 \mathrm{~mm}$ away.

Methylated PITX2 was observed in all samples including control tissues (fig. 1d). Compared with benign tissues, significantly increased PITX2 hypermethylation (38.3-90.9\%) was present in $80 \%$ of the carcinoma specimens $(20 / 25)$ and in 2 of 3 PIN foci $(p<0.0001)$. Two peritumoral tissues showed elevated methylation levels (sample 14, $3 \mathrm{~mm}$ away from the tumor, and sample 23, $20 \mathrm{~mm}$ away from the tumor).

\section{Gene Promoter Hypermethylation in Comparison} with Standard Pathological Parameters

We compared methylation ratios of the tumor tissues with $\mathrm{pT}$ category and primary Gleason grade. GSTP1 hypermethylation was significantly associated with a higher $\mathrm{pT}$ stage $(\mathrm{p}=0.006$, fig. $2 \mathrm{a})$ and a higher primary Glea- son grade ( $\mathrm{p}=0.021$, fig. $2 \mathrm{~b})$. The same correlation with Gleason grade could be demonstrated for RAR $\beta 2$ ( $p=$ 0.018 ; fig. $2 b)$ and APC ( $p=0.021$; fig. $2 b)$, respectively, whereas a relationship with $\mathrm{pT}$ stage for both of these genes could not be shown. PITX2 hypermethylation was not associated with any of the 2 parameters.

Interestingly, we found a weak correlation between patient ages and GSTP1 $\left(\mathrm{r}_{\mathrm{s}}=0.424, \mathrm{p}=0.035\right.$, data not shown) and PITX2 methylation $\left(\mathrm{r}_{\mathrm{s}}=0.432, \mathrm{p}=0.031\right.$, data not shown).

\section{Discussion}

PCa detection at an early stage is still a great challenge since clinical imaging is often not able to detect a tumor and biopsies may miss the tumor focus.

Gene promoter hypermethylation seems to be involved in prostate carcinogenesis, and its analysis might be able to improve PCa diagnosis [11, 14, 22-24]. Furthermore, if the theory of an epigenetic field effect is applied to $\mathrm{PCa}$, it should be possible to demonstrate changes in tumor-adjacent, histologically unequivocal tissue specimens. Thus, we compared the promoter methylation status of GSTP1, RAR $\beta 2$, APC and PITX2 in histologically verified PCa with tumor-adjacent tissues. Completely PCa-free tissues from patients who underwent radical cystoprostatectomies because of bladder cancer served as controls. 
RAR $\beta 2$ seems to be the most promising gene we analyzed since its methylation is nearly absent in control tissues and elevated in PIN and PCa, suggesting this gene to be suitable for the detection of neoplastic lesions in the prostate. Furthermore, due to the fact that we were able to identify higher methylation ratios in tumor-adjacent tissue samples, this gene could also be useful for the detection of patients at risk for PCa in biopsies that are histologically tumor-free. We also identified a statistically significant association between RAR $\beta 2$ methylation and primary Gleason grade.

Despite the fact that most tumor samples showed welldetectable GSTP1 methylation levels, neither controls nor tumor-adjacent tissues were hypermethylated which is consistent with the results of several other research groups $[18,25,26]$. On the other hand, Hanson and colleagues [17] showed a kind of methylation field effect for this gene when analyzing stromal cells in the prostate using microdissection. But, in contrast to our experiments, they did not document the exact distances of the benign samples relative to the tumor. Rabiau et al. [27] also demonstrated higher GSTP1 methylation ratios in 3 samples of peritumoral and in 15 non-malignant prostatic tissues. In our study, GSTP1 methylation was a specific marker for PIN and PCa and was found to be absent in tumoradjacent tissues, speaking in favor of the purity of the tissue cores retrieved. Thus, our results clearly point towards a high sensitivity of GSTP1 hypermethylation to detect neoplastic prostatic tissue.

Furthermore, we were able to demonstrate a relationship between the GSTP1 methylation extent and pT stage as well as primary Gleason grade. Zhou et al. [28] tested 109 biopsies of 40 patients and found significantly increased GSTP1 methylation levels with higher Gleason grade tumors as well. The same results were recently demonstrated by Richiardi et al. [29] after analyzing 243 patients diagnosed in the pre-PSA era, but not in another cohort diagnosed later. Bastian et al. [23] could not demonstrate a link between hypermethylation and tumor progression when focusing on a single gene locus, but found a significant correlation when analyzing the results of combined gene loci relating to clinicopathological parameters.

Both APC and PITX2 promoter methylation were recently identified as prognostic factors [14, 29]. Peritumoral tissue of only 2 specimens for PITX2 and of 5 samples for APC, respectively, showed increased methylation levels suggesting that APC and PITX2 methylation occurs rarely in tumor-adjacent tissue.

We did not find a correlation between PITX2 methylation and tumor stage and Gleason grade. This is consistent

DNA Promoter Methylation in Prostate

Cancer with the findings of Weiss and colleagues [14] who reported PITX2 hypermethylation to be a prognostic factor independent of standard clinicopathologic parameters in tissue samples of 605 patients. Thus, it could be possible that methylation of PITX2 is associated with disease-free survival rather than with pathologic parameters.

With regard to APC methylation in the tumor, we observed a correlation between elevated ratios and primary Gleason grades, which is in line with the findings of Richiardi and colleagues [29] in a cohort of 243 patients.

For both GSTP1 and PITX2 methylation, we identified an age-related correlation. Such a connection was previously described by Kwabi-Addo et al. [30] for GSTP1 methylation in normal prostatic tissue. Thus, elevated GSTP1 and PITX2 methylation ratios are probably caused to some extent by an advanced age of the patients. The fact that PCa mainly occurs in older men is in line with the finding that epigenetic changes, which are believed to play a role in carcinogenesis, increase with age.

Some limits of the present study should be discussed. First of all, we did not use laser capture microdissection of tissue for our experiments. Nevertheless, each sample was carefully mapped for tumor foci by several histologic step sections, assuring a high tumor cell content $(>70 \%)$ in the tumor specimens and an absence of tumor cells in the specimens assigned as 'tumor-free'. Furthermore, the dissection approach we used (histologically controlled punch biopsy) comes closer to the methods usually applied in routine diagnostics. Notably, GSTP1 methylation as a specific marker for PIN and PCa $[18,25,26]$ was found to be absent in tumor-adjacent tissue speaking in favor of the purity of the tissue cores retrieved. Second, different PCR-based assays were used to quantify the extent of the methylated gene. However, we mainly used commercialized PCR assays which worked accurately, and the primers for RAR $\beta 2$, APC and ACTB had already been established in the literature. Third, the number of prostate cancer cases in our study is rather small. The primary goal of our study was to investigate a putative methylation field effect. Therefore, we decided to analyze multiple tissue samples from few prostatectomy specimens rather than a higher number of tumors. However, for the observed association of several methylation markers with Gleason grade and tumor stage, larger studies are clearly needed to validate these results.

To summarize our data, GSTP1 methylation analysis seems to be the most sensitive tool to discriminate between neoplastic lesions and normal prostatic tissues, and RAR $\beta 2$ could be a promising candidate for assessing a PCa risk in histological tumor-free biopsies.

Pathobiology 2010;77:260-266 


\section{References}

1 Neal DE, Donovan JL: Prostate cancer: to screen or not to screen? Lancet Oncol 2000; 1:17-24.

$>2$ Catalona WJ, Smith DS, Ratliff TL, Dodds KM, Coplen DE, Yuan JJ, Petros JA, Andriole GL: Measurement of prostate-specific antigen in serum as a screening test for prostate cancer. N Engl J Med 1991;324:1156-1161.

3 Catalona WJ, Partin AW, Slawin KM, Naughton CK, Brawer MK, Flanigan RC, Richie JP, Patel A, Walsh PC, Scardino PT, Lange PH, deKernion JB, Southwick PC, Loveland KG, Parson RE, Gasior GH: Percentage of free PSA in black versus white men for detection and staging of prostate cancer: a prospective multicenter clinical trial. Urology 2000;55:372-376.

$\checkmark 4$ Jones PA, Baylin SB: The fundamental role of epigenetic events in cancer. Nat Rev Genet 2002;3:415-428.

$>5$ Jones PA, Laird PW: Cancer epigenetics comes of age. Nat Genet 1999;21:163-167.

6 Herman JG, Baylin SB: Gene silencing in cancer in association with promoter hypermethylation. N Engl J Med 2003;349:20422054.

$>7$ Lin X, Tascilar M, Lee WH, Vles WJ, Lee BH, Veeraswamy R, Asgari K, Freije D, van RB, Gage WR, Bova GS, Isaacs WB, Brooks JD, Deweese TL, De Marzo AM, Nelson WG: GSTP1 CpG island hypermethylation is responsible for the absence of GSTP1 expression in human prostate cancer cells. Am J Pathol 2001;159:1815-1826.

$>8$ Lee WH, Morton RA, Epstein JI, Brooks JD, Campbell PA, Bova GS, Hsieh WS, Isaacs WB, Nelson WG: Cytidine methylation of regulatory sequences near the pi-class glutathione S-transferase gene accompanies human prostatic carcinogenesis. Proc Natl Acad Sci USA 1994;91:11733-11737.

$>9$ Nelson WG, De Marzo AM, Deweese TL, Lin X, Brooks JD, Putzi MJ, Nelson CP, Groopman JD, Kensler TW: Preneoplastic prostate lesions: an opportunity for prostate cancer prevention. Ann NY Acad Sci 2001;952:135 144.

$\checkmark 10$ Jeronimo C, Henrique R, Hoque MO, Ribeiro FR, Oliveira J, Fonseca D, Teixeira MR, Lopes C, Sidransky D: Quantitative RARbeta2 hypermethylation: a promising prostate cancer marker. Clin Cancer Res 2004; 10 4010-4014.
11 Kang GH, Lee S, Lee HJ, Hwang KS: Aberrant $\mathrm{CpG}$ island hypermethylation of multiple genes in prostate cancer and prostatic intraepithelial neoplasia. J Pathol 2004;202: 233-240.

12 Esteller M, Corn PG, Baylin SB, Herman JG: A gene hypermethylation profile of human cancer. Cancer Res 2001;61:3225-3229.

13 Henrique R, Ribeiro FR, Fonseca D, Hoque MO, Carvalho AL, Costa VL, Pinto M, Oliveira J, Teixeira MR, Sidransky D, Jeronimo C: High promoter methylation levels of APC predict poor prognosis in sextant biopsies from prostate cancer patients. Clin Cancer Res 2007;13:6122-6129.

14 Weiss G, Cottrell S, Distler J, Schatz P, Kristiansen G, Ittmann M, Haefliger C, Lesche R, Hartmann A, Corman J, Wheeler T: DNA methylation of the PITX2 gene promoter region is a strong independent prognostic marker of biochemical recurrence in patients with prostate cancer after radical prostatectomy. J Urol 2009;181:1678-1685.

15 Slaughter DP, Southwick HW, Smejkal W: Field cancerization in oral stratified squamous epithelium; clinical implications of multicentric origin. Cancer 1953;6:963-968.

16 Vauthey JN, Walsh GL, Vlastos G, Lauwers GY: Importance of field cancerisation in clinical oncology. Lancet Oncol 2000;1:1516.

17 Hanson JA, Gillespie JW, Grover A, Tangrea MA, Chuaqui RF, Emmert-Buck MR, Tangrea JA, Libutti SK, Linehan WM, Woodson KG: Gene promoter methylation in prostate tumor-associated stromal cells. J Natl Cancer Inst 2006;98:255-261.

-18 Mehrotra J, Varde S, Wang H, Chiu H, Vargo J, Gray K, Nagle RB, Neri JR, Mazumder A: Quantitative, spatial resolution of the epigenetic field effect in prostate cancer. Prostate 2008;68:152-160.

19 Distler J: Quantification of methylated DNA by HeavyMethyl duplex PCR. Methods Mol Biol 2009;507:339-346.

20 Harden SV, Tokumaru Y, Westra WH, Goodman S, Ahrendt SA, Yang SC, Sidransky D: Gene promoter hypermethylation in tumors and lymph nodes of stage I lung cancer patients. Clin Cancer Res 2003;9:13701375.

21 Eads CA, Danenberg KD, Kawakami K, Saltz LB, Blake C, Shibata D, Danenberg PV, Laird PW: MethyLight: a high-throughput assay to measure DNA methylation. Nucleic Acids Res 2000;28:E32.
22 Yegnasubramanian S, Kowalski J, Gonzalgo ML, Zahurak M, Piantadosi S, Walsh PC, Bova GS, De Marzo AM, Isaacs WB, Nelson WG: Hypermethylation of $\mathrm{CpG}$ islands in primary and metastatic human prostate cancer. Cancer Res 2004;64:1975-1986.

23 Bastian PJ, Ellinger J, Wellmann A, Wernert N, Heukamp LC, Muller SC, von Ruecker A: Diagnostic and prognostic information in prostate cancer with the help of a small set of hypermethylated gene loci. Clin Cancer Res 2005;11:4097-4106.

24 Tokumaru Y, Harden SV, Sun DI, Yamashita K, Epstein JI, Sidransky D: Optimal use of a panel of methylation markers with GSTP1 hypermethylation in the diagnosis of prostate adenocarcinoma. Clin Cancer Res 2004; 10:5518-5522.

25 Nakayama M, Bennett CJ, Hicks JL, Epstein JI, Platz EA, Nelson WG, De Marzo AM: Hypermethylation of the human glutathione S-transferase-pi gene (GSTP1) CpG island is present in a subset of proliferative inflammatory atrophy lesions but not in normal or hyperplastic epithelium of the prostate: a detailed study using laser-capture microdissection. Am J Pathol 2003;163:923-933.

26 Goessl C, Krause H, Muller M, Heicappell R, Schrader M, Sachsinger J, Miller K: Fluorescent methylation-specific polymerase chain reaction for DNA-based detection of prostate cancer in bodily fluids. Cancer Res 2000; 60:5941-5945.

27 Rabiau N, Thiam MO, Satih S, Guy L, Kemeny JL, Boiteux JP, Fontana L, Bignon YJ, Bernard-Gallon D: Methylation analysis of BRCA1, RASSF1, GSTP1 and EPHB2 promoters in prostate biopsies according to different degrees of malignancy. In Vivo 2009; 23:387-391.

28 Zhou M, Tokumaru Y, Sidransky D, Epstein JI: Quantitative GSTP1 methylation levels correlate with Gleason grade and tumor volume in prostate needle biopsies. J Urol 2004; 171:2195-2198.

29 Richiardi L, Fiano V, Vizzini L, De ML, Delsedime L, Akre O, Tos AG, Merletti F: Promoter methylation in APC, RUNX3, and GSTP1 and mortality in prostate cancer patients. J Clin Oncol 2009;27:3161-3168.

30 Kwabi-Addo B, Chung W, Shen L, Ittmann M, Wheeler T, Jelinek J, Issa JP: Age-related DNA methylation changes in normal human prostate tissues. Clin Cancer Res 2007;13: 3796-3802.
Steiner/Jung/Schatz/Horns/ Wittschieber/Lein/Dietel/Erbersdobler 